\title{
Instructional Strategies in Teaching Engineering at a Distance: Faculty Perspective
}

\author{
S. Anbahan Ariadurai and Rajalingam Manohanthan \\ The Open University of Sri Lanka
}

\begin{abstract}
This paper presents research on a convenience sample of the Open University of Sri Lanka's engineering faculty. Examined in this research are faculty's opinions on the instructional strategies they use to teach engineering courses at a distance. First, this paper details the pedagogical strategies used by the faculty, which is then followed by an overview of faculty's opinions on the strengths and weaknesses of engineering courses offered by the Open University of Sri Lanka. Recommendations are given to improve the overall effectiveness of the engineering courses. It is anticipated the adoption of these recommendations will result in greater student competency and lower drop-out rates.
\end{abstract}

Keywords: Distance learning; engineering; instructional strategy; Sri Lanka

\section{Introduction}

The abstract nature of engineering makes this subject difficult to teach in any educational environment, and more so at a distance. Teaching engineering at a distance by its inherent nature introduces additional challenges. Engineering education typically requires students to have physical knowledge that only lab activities and hands-on experiences can provide (Da Silveira, Da Silva \& Térsio, 1999).

The Faculty of Engineering Technology of the Open University of Sri Lanka (OUSL) has been offering distance education courses in engineering for 20 years. The blended learning system used by OUSL's Faculty of Engineering Technology is based on multimedia instructional materials, with strong emphasis placed on distance education using printed material and audio-visual aids. Self directed study is the central theme of study at OUSL; students are typically provided printbased learning materials in lieu of attending conventional face-to-face university lectures. These print-based learning materials provide students with learning activities and self-assessments in the form of questions designed to help them develop independent study and analytical skills. At OUSL, print-based study materials are supported by audio-visual learning materials, attendance at day schools (i.e., face-to-face tutorials), consultation sessions, laboratory work, field work, and seminars. Laboratory work and field work, which are both compulsory components, form an integral part of OUSL's engineering technology programme. While attending the day schools, OUSL students are encouraged to discuss difficulties they may have encountered in the self study materials. In recent years, limited Web-based support has been provided for some courses within 
OUSL's engineering programme. Most students, however, lack access to the Internet (and webbased learning) so this form of learning support is not compulsory for this programme. Indeed, only students with access to the Internet are able to utilize this form of student and learning support.

OUSL's Faculty of Engineering Technology's curriculum enables students to structure their coursework to meet their individual learning needs and lifestyle. All programmes are designed to lead to a recognized degree qualification. Depending on the courses selected and credit hours earned, OUSL's students are then awarded the diploma or degree with specialization in a particular field of study (e.g., civil engineering).

OUSL's engineering programmes comprise a number of courses, all which fall into distinct subtopics of study such as: industrial courses, general courses, computer literacy, English, management, training, engineering courses, engineering projects, and mathematics. Each course is assigned a 'Level' ranging between zero (0) and seven (7). Each course in a programme of study is assessed separately. Assessments consist of two components: continuous assessment and the final examination. Learning activities, such as laboratory work, field classes, assignments, presentations, mini projects, and assessments in the form of tests and examinations, comprise the components of continuous assessment of OUSL's engineering programme. In this programme, continuous assessment is one of the more important means of facilitating learning and for monitoring students' progress. The final grade point received for a given course of study depends solely on students' performance which, as noted, is based on continuous assessment and the results of the final examination.

\section{Rationale for the Current Study}

Much comparative research has been done examining the effectiveness of various instructional strategies used by distance education institutions, such as the effectiveness of a given delivery system or technology versus another. In most literature, comparative studies examining delivery systems in distance education report no significant differences in learning (Hoyte \& Frye, 1972; Chu \& Schramm, 1975; Whittington, 1987; Bacon \& Jakovich, 2001). According to Dillon, Hengst and Zoller (1991), however, these "comparison studies" generally find either no significant differences in learning or significant differences in favor of the distance students. Some studies suggest that the technology used to support instruction typically has little influence on student learning outcomes (Johnson \& Aragon, 2003). Factors, such as the unique attributes of the technology (Denton \& Clark, 1985), the type of learning outcome desired, or the method used (Dillon \& Strohmeyer, 1991) are rarely investigated, however. The question our research seeks to answer is not whether to use technology per say, but rather how best to use it (Chu \& Schramm, 1975).

OUSL's Faculty of Engineering Technology is, in many respects, a true pioneer, in that OUSL is one of the first open and distance learning universities in the world to offer engineering programmes at a distance. OUSL's Faculty of Engineering Technology has incorporated many instructional strategies in its engineering courses offered at a distance, and on the surface, OUSL appears to have been rather successful in producing many graduates and diploma holders in the field of engineering sciences (note: OUSL's diploma programme is an entry point to a full degree). It is not enough, however, to simply appear to be successful. On the contrary, it is important to undertake research to honestly determine whether or not distance courses are effective, and more importantly, to determine where and how improvements can be made. This 
paper presents the outcomes of study on the efficacy of the blended instructional strategies used by OUSL's Faculty of Engineering Technology. It is anticipated that this research will help inform others seeking to implement similar programmes offered at a distance.

\section{Sample}

A convenience sample of 11 faculty members was selected for this study. Those selected for this study were all responsible for teaching engineering at OUSL, using blended education instructional methods. The purpose of this research was to elicit faculty's opinions and ideas on possible initiatives and remedies to make the delivery of engineering courses at the OUSL more effective. This paper presents the findings of this study.

\section{Method}

Eleven $(n=11)$ faculty members were questioned on various aspects of educational programmes offered by OUSL's Faculty of Engineering Technology. Faculty were questioned to determine the sample's demographic profile and to solicit their opinions of the methods used for teaching distance engineering courses at the OUSL. This research also sought to determine faculty's opinions on core instructional methods: i.e., day schools, student support, and student performance. This research also sought to determine faculty's overall job satisfaction with OUSL's Faculty of Engineering Technology. Confidentiality was maintained by using pseudonyms when analyzing the data. The data obtained then underwent content analysis using contextual analysis on pre-determined topics.

To ensure the interviews would be representative of OUSL's entire Faculty of Engineering Technology, faculty from all the six departments were interviewed: (a) Agriculture and Plantation; (b) Civil; (c) Electrical and Computer; (d) Mechanical; (e) Textile and Apparel; (f) Mathematics and Philosophy of Engineering. Of the sample $(n=11)$, two were females and nine were males. Respondents' ages ranged from 32 to 64 years, yielding an average age of 49 years. Faculty's teaching experience ranged from five years to 24 years, yielding an average teaching experience of 13 years. None had experience with teaching in a distance education setting prior to joining OUSL. Of the 11 respondents interviewed, two indicated that they had traditional academic teaching experience; three had both industrial and traditional academic teaching experience; four had only industrial experience; while two were wholly new to teaching, having neither taught industrial or academic courses. Although all reported that they lacked experience teaching at a distance, all faculty interviewed held the opinion that engineering could be taught at a distance, but only if proper arrangements were made to ensure practical hands-on course components are incorporated.

\section{Blended Instructional Strategies at OUSL}

Faculty members' opinion was solicited on the blended system OUSL adopted to teach engineering skills. Most faculty interviewed agreed that the current blend of instruction comprised of face-to-face components like laboratory classes, field camps, day schools, and tutorial clinics, coupled with print-based instructional materials, seemed to work well. They also opined that in order to teach students engineering knowledge and skills, face-to-face sessions remain necessary. This finding echoes research done by Bilham and Gilmour (1995), who found 
that no matter how well designed, engineering courses delivered at a distance will need face-toface and hands-on components to be successful.

Faculty further reported that the blended instructional strategy employed by OUSL's Faculty of Engineering Technology lacks sufficient variety of distance educational materials. Although custom-designed print-based course materials were reported to be one of the strong points of OUSL's engineering distance programme (remember, many OUSL students lack adequate access to computers) those interviewed also stressed that the engineering courses taught at a distance could also benefit from the use of supplementary audiovisual learning materials and learning aids. They also opined, however, that only students with a good command of English could easily understand the learning materials; whereas those that do not have a strong command of English would need the help of an intermediary, face-to-face tutor. Though faculty members generally agreed that OUSL's print-based learning materials were adequate, some indicated that some of the teaching materials were out-of-date, a finding that suggests the need for OUSL to perform regular and systematic updates of its print-based learning materials for its engineering programmes of study.

Respondents reported that the current blended method of teaching does have several strong points. For example, 'student performance' was identified by faculty as a strong component of the programme. Laboratory classes, tutor-marked assignments, and continuous assessments, were similarly viewed as strong points of the programme. The industrial training component, which exposes students to hands-on work settings, was also viewed as a strong point. Finally, faculty reported that the delivery methods designed to improve students' information gathering and presentation skills was also a strong point of the programme.

Faculty, however, did report some weaknesses with the current blended system of instruction used in the engineering programme. They indicated that greater emphasis must be placed on teaching students how to learn, how to think, and how to do, instead of simply having them regurgitate memorized facts, procedures, and so forth. In short, faculty felt students were not ready for study at a distance. Faculty noted, however, that students' over reliance on rote learning could be largely attributed to traditional 'sage-on-the-stage' pedagogies used in Sri Lanka's secondary school system. Indeed, in Sri Lanka most view higher education as a means to a better life and livelihood. And although access to post-secondary education is free and open to all, the reality is that competition to gain entrance into Sri Lanka's so-called best post-secondary institutions can be very intense indeed. Students are 'differentiated' based on their educational attainment levels. Those scoring the highest grades are typically granted admission into Sri Lanka's 'best' post secondary institutions. In cultural terms, 'better' educational qualifications typically lead to better paying jobs (Little, 1997). In Sri Lanka, such cultural norms remain firmly entrenched. To ensure that their sons or daughters get into Sri Lanka's so-called top universities, high school students tend to be 'spoon-fed' by their teachers. Moreover, many high school aged students benefit from parents who are willing to pay for private tutors that give them a competitive edge they perceive they need. Such educational 'spoon feeding', however, leaves many school leavers in poor shape to participate and benefit from independent, self-guided study needed to succeed in distance education. In order to overcome this apparent deficit, it has been suggested that 'project based' learning should be increased in distance education programmes. William Heard Kilpatrick, who pioneered project-based learning in the early 1900s, advocated the use of student-chosen projects that engender purposeful activity. When students are allowed to choose what they want to learn and explore, they become intrinsically motivated to work harder and strive for the highest quality (Wolk, 1994). However, because peer pressure is on Sri Lanka's students to get into the best school often irrespective of their intrinsic desires, many are 'spoon fed.' 
In this study, those faculty interviewed suggested that more weight be given to continuous assessment (i.e., project-based work) and less weight placed on the final examination results. Those interviewed also suggested that students should be encouraged to be gainfully employed while studying at a distance, as this would give them more opportunity to apply the new skills they have learned on the job. For those students who are unemployed, faculty opined that they could gain competency and proficiency during their industrial work placements. Many interviewed felt that the integration of distance learning with paid work would reduce the need for face-to-face laboratory sessions, which are currently integral to most engineering based courses offered by OUSL. This view is supported by Deshpande and Ashtikar (2005) who reported that when curriculum is carefully prepared and the delivery medium selected accordingly, and then integrated with real work outcomes, the actual need for hands-on, face-to-face teaching can be significantly reduced. The reduction of time spent on engineering course practice sessions holds significant cost advantages, which in turn, can lead to more effective utilization of physical plants and facilities. Such 'freeing up' of physical resources could then allow for greater numbers of students to be trained.

Most faculty members interviewed felt that OUSL's Faculty of Engineering Technology should increase the variety of the instructional materials used. They also suggested improving Webbased learning materials and introducing computer-based evaluations. They also suggested using more audio-visual materials, video conferencing, multimedia-based lessons - all specially designed for online delivery.

Indeed, with the expansion of information and communication technologies many universities worldwide are now offering engineering related courses by distance education. These institutions have adopted various instructional strategies needed to impart necessary practical skills to students.

For example, Grimoni, Belico dos Reis, and Tori (1998) describe the success of using multimedia for their existing electrical engineering on-campus students. Kondo and Ishijima (1999) discuss a distance learning system for engineering education via the Internet, using multimedia technologies and mathematical tools for a course in control engineering. Lieberman and Cheung (2007) report on the development of remote-controlled laboratory exercises for their distance laser and fibre-optics engineering technology programme. To address problems inherent in handson laboratories and teaching such laboratories at a distance, many institutions now use computer simulations as an inexpensive way to expose more students to the power of real laboratories without them having to incur the burden of costs associated with time and travel. Simulation software enables delivery of laboratory facilities to the front door of students' homes (Gorrell, 1992). Constant software upgrades have also resulted in aggregate improvements in distance education (Thomas \& Hooper, 1991). Internet-based simulations can be used flexibly by students anytime, anywhere. According to Alhalabi, Marcovitz, Hamza and Petrie (2004), however, although simulations can serve important purposes, in some cases, such simulations are an inadequate substitute for real, hands-on laboratory experiences. Although simulation serves the purpose of initial experimentation, these authors opined that it cannot provide the same range of possibilities that manipulating physical material does. In some fields, such as electrical and mechanical engineering, actual experiences with real physical elements are necessary.

Based on these extensive studies, the conclusion was drawn that the inherent weakness of courses taught via the Internet that require laboratory experiments is that they lack non-concrete representation of reality. Some indicated, however, that this weakness could be offset by introducing virtual labs that allow students to perform experiments via the Internet (Hamza, Perez, \& Checker, 2001). 
Instructional Strategies in Teaching Engineering at a Distance: Faculty Perspective Ariadurai \& Manohanthan

\section{OUSL Day Schools}

Because most students lack access to computers and, by logical extension, access to the Internet, OUSL's day schools serve as the main face-to-face component in all its engineering courses. Faculty interviewed in this study were unanimous in declaring that the day schools are vitally important for students enrolled in OUSL's engineering programme. Most noted, however, that attendance in the day schools was poor at best, and for those students that did attend, most came to class ill prepared. Indeed, it was reported by faculty that most students expected to be lectured on - that is 'spoon fed' - the lesson materials. In light of this empirical observation, the Faculty of Engineering Technology's day schools could be viewed as failures. The good news is that many suggestions offered by engineering faculty interviewed for this study could make OUSL's day schools more meaningful and effective for students.

For instance, faculty suggested that poorly designed course materials could be the root cause of students coming to the day schools ill prepared. It was recommended, therefore, that the lesson materials be simplified and made more attractive to students. As the texts are in English, it was also recommended that efforts should be made to improve students' command of the English language. In addition, if students are armed with supplementary audio and video materials that interconnect with the printed learning materials, they will be tacitly encouraged to read the lesson materials, and thus arrive at the day schools better prepared. Use of supplementary online support and tools, such as PowerPoint presentations and video programmes, was recommended to make the day schools more contextually meaningful and interesting for students. Faculty also felt that providing students with a glossary of the technical terms could aid in comprehension. For example, some faculty members noted that students tend to stop studying if they come across unknown words or concepts, a finding that is supported in the literature by Pavani and Lukowiecki (2000) who found that engineering programmes should provide students quick and easy access to reference information. This finding clearly underscores the need for inclusion of

glossaries and reference materials in the design and development of OUSL's engineering course contents.

Faculty also reported that students do not come prepared for day schools, simply because they are unaware of how they should prepare for the day schools. It was suggested, therefore, that students be required to attend an orientation session prior to starting their programme of study, a session that stresses the difference between an OUSL day school and formal lectures at conventional universities. Faculty further suggested that students must be taught how to learn independently. It was noted that many students enrolled in OUSL's Faculty of Engineering Technology programmes drop-out simply because they are unsuited for the rigors of studying engineering sciences at a distance, often because they are more used to being 'spoon fed' information. To lower student drop-out rates and ensure that they are not wasting their valuable time, prescreening efforts that measures an individual's readiness for distance learning should be mandatory for all wishing to enroll in OUSL's engineering programme. Finally, one faculty member went so far as to suggest that students who come to the day schools unprepared, should be sent home immediately, which would impress upon them the importance of being fully prepared for the day school sessions.

\section{Student Support}

Faculty members were asked their opinions of the various forms of student support provided by OUSL's Faculty of Engineering Technology. Most were divided on the issue of student support, with some faculty reporting that the student support provided was adequate, while others 
determined it was inadequate. One faculty member in particular stressed his dissatisfaction with the "temporary demonstrators" that lacked both adequate academic standing and training to give proper guidance to students. This faculty member also suggested that laboratory classes should be arranged to take place on weekends, simply because gainfully employed students found it difficult to attend on weekdays. Another suggestion offered by faculty members was that all faculty should be more proactive in providing students with needed support, and that the Faculty of Engineering Technology should have dedicated staff located in OUSL's regional and study centres.

Further, a change in university culture was recommended by those faculty interviewed. In simple terms, it was felt that all OUSL's academic and administrative staff should strive to provide a more proactive and supportive learning environment for its students. Customer service and accountability is central to such a scenario according to those interviewed. Most interviewed felt that all faculty and staff must embrace a culture premised on their genuine commitment to student success. They opined that OUSL staff and faculty must be empowered to take control for their own job roles and responsibilities, and that all must be held fully responsible for their own job and teaching performance.

On the other hand, in light of limited resources currently available at OUSL, some respondents reported that they were satisfied with the support provided by the Faculty of Engineering Technology. Nonetheless, they also pointed out that improvements in library and Internet facilities were needed at all OUSL's study/ regional centres. One faculty member pointedly suggested that teacher-to-student interaction could be increased by assigning between 25-50 students to one tutor and that the sole purpose of this tutor would be to discuss personal and academic problems. It was also opined that student support could be improved through simple measures, such as sending course and programme information materials to students on time (i.e., timeliness was noted to be a problem). It was also suggested that students could benefit greatly by helping them find industrial training placements.

\section{Student Performance}

Faculty members were queried on student performance, a contentious area in which none interviewed expressed satisfaction. Faculty offered a number of explanations for students' poor performance and suggested ways in which such performance could be improved. These responses are summarized in Table 1 (next page). 
Instructional Strategies in Teaching Engineering at a Distance: Faculty Perspective Ariadurai \& Manohanthan

Table 1. Root causes of poor student performance and suggested remedial actions

Root causes for Poor Student
Performance

o Students do not adapt themselves to learn at a distance

o Students join the programme with unrealistic expectations that do not match the objectives of the courses/programme

o Students do not know what they are getting through the ODL.

o Workload is excessive for working students.

- Students do not prepare for day schools.

o Non proficiency in English

- Students not capable of doing engineering subjects are enrolled into the programme

$0 \quad$ The way the courses are presented and delivered may not be to the liking of the students o Applicants must be screened on the basis of their ability to learn through distance education.

o When they join the university, initial courses must be delivered in a more conventional way; distance teaching courses should be introduced gradually as students progress through the programme.

o The orientation of courses must be changed from teacher-centred to learner-centred.

o Overall changes in method of education from school level must be introduced.

o Student must be trained to do "self studies".

o Proper counselling should be done before and during the registration o English language support must be provided to enable students to improve their language ability. o Applicants must be screened on their ability to follow engineering-related courses.

o The instructional package and teaching must be improved 
Instructional Strategies in Teaching Engineering at a Distance: Faculty Perspective

Ariadurai \& Manohanthan

\section{Faculty Satisfaction}

The final phase of the interview focused on job satisfaction. Eight $(n=8)$ faculty members reported that they were generally satisfied with their work at the Faculty of Engineering Technology. Three faculty members $(n=3)$ reported that they were not satisfied. Unlike teaching at a conventional university, teaching at OUSL was felt to be challenging and offered rewarding new experiences each day. One faculty member reported that the distance learning environment increases access to serve more students. According to this particular faculty member, "the future of education lies in distance education." Some faculty reported distance education to be a good vehicle for engineering education, simply because this mode of educational delivery encourages independent learning. In other words, learning how to learn independently was thought to be necessary for helping future graduates rise to real-life challenges they will face everyday on the job. Another reported advantage was that distance education can expand access by enabling mature students to benefit from a university-level education, all while working and tending to their families. Further, many faculty felt OUSL exposes its students to wider issues concerning teaching and learning than a conventional university. One faculty member, however, reported dissatisfaction at the lack of additional institutional support for those who work beyond their routine duties.

\section{Conclusions}

The study reported in this paper yields many useful insights into various aspects of the instructional strategies currently employed by OUSL's Faculty of Engineering Technology. Faculty members' views on print-based materials was mixed. While the availability of printbased materials and student evaluation were identified as strong points, faculty reported that one of the main constraints facing OUSL's Faculty of Engineering Technology is that it currently lacks sufficient variety in the distance learning materials used. Those interviewed also noted that students were generally unprepared for the day schools, but many suggested measures to remedy this problem. Students' lacking independent learning skills was similarly identified by faculty as one of the greatest obstacles to teaching at a distance; many constructive suggestions, however, were given that could help students adapt to learning at a distance. None of the faculty interviewed reported being satisfied with their students' performance; however, many useful suggestions were offered on how to improve student performance. Finally, most faculty members interviewed were generally satisfied with their work at the Open University of Sri Lanka.

\section{References}

Alhalabi, B., Marcovitz, D., Hamza, K., \& Petrie, M. (2004). Remote Labs: An innovative leap in the world of distance education. Journal of Chemical Education, 81(1), 1814-1816.

Bacon, S. F., \& Jakovich, J. A. (2001). Instructional television versus traditional teaching of an introductory psychology course. Teaching of Psychology, 28(2), 88-92.

Bilham, T., \& Gilmour, R. (1995). Distance Education in Engineering for Developing Countries. Education Research: Serial No. 13. London: Overseas Development Association. 
Chu, G., \& Schramm, W. (1975). Learning from television: What the research says. Washington DC.: National Association of Educational Broadcasters.

Da Silveira, M., Da Silva, A., \& Carlos Térsio, C. (1999). Hands-on courses change students. Proceedings of the 1999 International Conference on Engineering Education. August 1014, Prague. http://www.fs.vsb.cz/akce/1999/ICEE99/Proceedings/index.htm

Denton, J. J., \& Clark, F. E. (1985). Assessing instructional strategies and resulting student attitudes regarding two-way television instruction. Journal of Educational Technology Systems, 13(4), 281-298.

Deshpande, S. G., \& Ashtikar, R. (2005). SWOT analysis of distance education for testing its suitability to impart technical and vocational education. Proceedings of the 2005 International ICDE Conference. November 19-23, New Delhi. http://www.ignou.ac.in/ICDE2005/PDFs/theme3pdf/theme3_188.pdf

Dillon, C., \& Strohmeyer, E. (1983). The effects of telecommunications instruction on student achievement and attitude. Montana Educational Review, 7-9.

Dillon, C. L., Hengst, H. R., \& Zoller, D. (1991), Instructional strategies and student involvement in distance education: A study of the Oklahoma televised instruction system. Journal of Distance Education, 6(1). http://cade.icaap.org/vol6.1/8 dillon.html

Grimoni, J. A. B., Belico dos Reis, L., \& Tori, R. (1998). The use of multimedia in engineering education - An experience. ERIC Document No.: 443731. http://www.eric.ed.gov/ERICDocs/data/ericdocs2sql/content_storage_01/0000019b/80/1 $\underline{6 / 5 \mathrm{a} / 55 . p d f}$

Gorrell, J. (1992). Outcomes of using computer simulations. Journal of Research on Computing in Education, 24(3), 359-366.

Hamza, M. K., Perez, B., \& Checker, C. (2001). Creative leaps in distance education technologies. Journal of Online Learning, 12(1). http://www.iste.org/Content/NavigationMenu/Membership/SIGs/SIGTel Telelearning /S IGTel Bulletin2/Archive/20012/2001JuneHamza.htm

Hoyte, D. P., \& Frye, D. W. M. (1972). Effectiveness of telecommunications as an educational delivery system: Final report. (Project No. G035, Grant No. OEC-7- 72-0008 [509]). Washington, DC.: U.S. Department of Health, Education and Welfare, Office of Education, National Center for Educational Research and Development.

Johnson, S. D., \& Aragon, S. R. (2003). An instructional strategy framework for online learning environments. New Directions for Adult and Continuing Education, 100, 31-43.

Kondo, H., \& Ishijima, S. (1999). Tool based multimedia distance learning system for engineering education. Proceedings of the 1999 IEEE International Conference on Systems, Man, and Cybernetics, 2, October 12-15. http://ieeexplore.ieee.org/iel5/6569/17632/00825264.pdf

Lieberman, D. H., \& Cheung, T. D. (2007). Remote-controlled photonics laboratories for distance learning, Proceedings of the Seventh International Conference on Education and Training in Optics and Photonics. June 3-5. Ottawa. 290-298. 
Little, A. W. (1997). The value of examination success in Sri Lanka 1971-1996: The effects of ethnicity, political patronage and youth insurgency. Assessment in Education: Principles, Policy \& Practice, 4(1), 67-86

Pavani, A. M. B., \& Lukowiecki, A. L. S. (2000). Engineering distance learning: Development of course contents. Proceedings of the 2000 International Conference on Engineering Education. August 14-18, Taipei.

http://www.ineer.org/Events/ICEE2000/Proceedings/papers/MC2-3.pdf

Thomas, R., \& Hooper, E. (1991). Simulations: An opportunity we are missing. Journal of Research on Computing in Education, 23(4), 497-513.

Whittington, N. (1987). Is instructional television educationally effective? A research review. The American Journal of Distance Education, 1(1), 47-57.

Wolk, S. (1994). Project-based learning: Pursuits with a purpose. Educational Leadership, 52(3), 42-45.

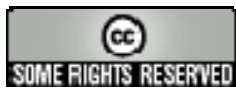

